\title{
Can the Induction of Labor with Misoprostol Increase Maternal Blood Loss?
}

\section{Pode a indução do parto com misoprostol aumentar a perda de sangue materna?}

\author{
Paulo César Praciano Souza ${ }^{1}$ Karla Santana Azevedo Damasceno ${ }^{1}$ Edward Araujo Júnior ${ }^{2}$ \\ Carlos Augusto Alencar Júnior ${ }^{1}$ Francisco Edson de Lucena Feitosa ${ }^{1}$ \\ ${ }^{1}$ Obstetrics Sector, Maternidade Escola Assis Chateaubriand, \\ Universidade Federal do Ceará (UFC), Fortaleza-CE, Brazil \\ 2 Department of Obstetrics, Escola Paulista de Medicina, Universidade \\ Federal de São Paulo (EPM-UNIFESP), São Paulo-SP, Brazil

\begin{abstract}
Address for correspondence Edward Araujo Júnior, PhD, Departmento de Obstetrícia, Escola Paulista de Medicina, Universidade Federal de São Paulo, Rua Belchior de Azevedo, 156, apto. 111, Torre Vitoria, 05089-030, São Paulo, SP, Brazil (e-mail: araujojred@terra.com.br).
\end{abstract}

Rev Bras Ginecol Obstet 2017;39:53-59.

\begin{abstract}
Keywords

- induced labor

- misoprostol

- postpartum hemorrhage

- hemoglobin

- vaginal birth
\end{abstract}

\section{Resumo}

received

June 19, 2016

accepted

October 21, 2016
Purpose To evaluate blood loss during misoprostol-induced vaginal births and during cesarean sections after attempted misoprostol induction.

Methods We conducted a prospective observational study in 101 pregnant women indicated for labor induction; pre- and postpartum hemoglobin levels were measured to estimate blood loss during delivery. Labor was induced by administering $25 \mu \mathrm{g}$ vaginal misoprostol every 6 hours (with a maximum of 6 doses). The control group included 30 patients who spontaneously entered labor, and 30 patients who underwent elective cesarean section. Pre- and postpartum hemoglobin levels were evaluated using the analysis of variance for repeated measurements, showing the effects of time (pre- and postpartum) and of the group (with and without misoprostol administration). Results There were significant differences between pre- and postpartum hemoglobin levels $(p<0.0001)$ with regard to misoprostol-induced vaginal deliveries $(1.6 \pm 1.4$ $\mathrm{mg} / \mathrm{dL})$, non-induced vaginal deliveries $(1.4 \pm 1.0 \mathrm{mg} / \mathrm{dL})$, cesarean sections after attempted misoprostol induction $(1.5 \pm 1.0 \mathrm{mg} / \mathrm{dL})$, and elective cesarean deliveries $(1.8 \pm 1.1 \mathrm{mg} / \mathrm{dL})$. However, the differences were proportional between the groups with and without misoprostol administration, for both cesarean $(p=0.6845)$ and vaginal deliveries $(p=0.2694)$.

Conclusions Labor induction using misoprostol did not affect blood loss during delivery.

Objetivo Avaliar a perda sanguínea em partos vaginais induzidos com misoprostol, e em cesáreas com tentativa prévia de indução do parto com misoprostol.

Métodos Realizou-se estudo prospectivo observacional com 101 gestantes com indicação para indução do trabalho de parto, as quais foram avaliadas pela dosagem de hemoglobina pré e pós-parto para estimativa da perda sanguínea no parto. Procedeu-se à indução do trabalho de parto com misoprostol $25 \mu \mathrm{g}$, via vaginal, a 


\section{Palavras-chave}

- trabalho de parto induzido

- misoprostol

- hemorragia pós-parto

- hemoglobina

- parto vaginal cada 6 horas, em um número máximo de 6 doses. O grupo controle foi composto por 30 pacientes que entraram em trabalho de parto espontaneamente, e por 30 pacientes que se submeteram a cesárea eletiva. O estudo da hemoglobina, antes e depois do parto, foi avaliado por ANOVA para medidas repetidas, no qual foi verificado o efeito do tempo (pré e pós-parto) e o efeito do grupo (com e sem uso do misoprostol).

Resultados Existem diferenças significativas entre os níveis de hemoglobina pré e pós-parto $(p<0,0001)$ nos partos vaginais induzidos pelo misoprostol $(1,6 \pm 1,4 \mathrm{mg} /$ $\mathrm{dL})$, nos partos vaginais não induzidos $(1,4 \pm 1,0 \mathrm{mg} / \mathrm{dL})$, nas cesáreas com tentativa prévia de indução $(1,5 \pm 1,0 \mathrm{mg} / \mathrm{dL})$, e nas cesáreas eletivas $(1,8 \pm 1,1 \mathrm{mg} / \mathrm{dL})$. Porém, as diferenças foram proporcionais em ambos os grupos, ou seja, ocorreu diferença tanto no grupo que fez uso do misoprostol quanto no grupo que não fez uso do medicamento, tanto na cesárea $(p=0,6845)$ quanto no parto vaginal $(p=0,2694)$. Conclusões $A$ indução do parto com misoprostol não alterou a perda sanguínea durante o parto.

\section{Introduction}

Misoprostol (15-deoxi-16-hydroxy-16-methyl prostaglandin E1) is a synthetic analog of prostaglandin E1. This drug was developed to treat and prevent gastrointestinal diseases, such as peptic ulcers associated with nonsteroidal anti-inflammatory drug use. ${ }^{1}$ Misoprostol exhibits various effects on the uterine cervix, essentially acting on the extracellular matrix. In addition, it relaxes the smooth muscles of the cervix and facilitates its expansion, simultaneously facilitating the increase of intracellular calcium and promoting mild uterine contractions. These mechanisms enable gradual cervical effacement and dilation concurrent with increased uterine activity, which ensures successful labor induction in most cases. ${ }^{2}$ Misoprostol exhibits low perinatal morbidity and mortality when administered at a dose of $25 \mu$ g every 6 hours, and is associated with a low risk of changes in uterine contractility and hyperstimulation syndrome. However, at a dose of $50 \mu \mathrm{g}$ every 4 hours, the incidence of meconium release is of $21.5 \%{ }^{3}$

In the obstetric clinical practice, blood loss is generally evaluated subjectively through visual assessment by the professionals in charge of the pregnant woman, or through the impact of the blood loss on the patient's hemodynamic stability, which varies among women and depends on their reserves. Some studies have indicated that the clinical estimation of postpartum bleeding has low scientific value., ${ }^{4,5}$ Estafan et $\mathrm{al}^{6}$ conducted a study to assess the accuracy of visually estimated blood loss during vaginal births and cesarean sections, correlating it with the postpartum decrease in hemoglobin. The clinical sensitivity to identify excessive blood loss was of $12 \%$ and $13 \%$ for vaginal birth and cesarean section respectively, and it was concluded that clinical estimates of blood loss during childbirth are subjective and arbitrary. Another study showed a low correlation between visual estimates of blood loss and perioperative changes in hemoglobin among women who underwent cesarean section. Thus, the analysis of hemoglobin dilution (that is, the decrease in hemoglobin concentration) after bleeding is a simple, inexpensive, and noninvasive means of estimating blood loss. ${ }^{7}$ A study showed that blood loss after oxytocin-induced labor ranged between 190 and $800 \mathrm{~mL}$, and that after misoprostol-induced labor, it ranged between 290 and $1200 \mathrm{~mL}$, which was statistically significant. Furthermore, the difference between the pre- and postpartum hematocrit was significantly higher in the misoprostol-induced labor group than in the oxytocin-induced labor group. ${ }^{8}$ Although the studies indicate greater postpartum blood loss after the misoprostol-induced labor, the effect of smaller doses of misoprostol on blood loss is yet controversial, because lower doses are associated with more gradual changes in the cervix.

Therefore, this study aimed to evaluate blood loss in pregnant women undergoing labor induced with $25 \mu \mathrm{g}$ of vaginal misoprostol every 6 hours by determining the difference between pre- and postpartum hemoglobin levels compared with blood loss during non-induced births.

\section{Methods}

A prospective observational study was conducted between January 2008 and January 2009 at the Maternidade Escola Assis Chateaubriand. This study was approved by the Research Ethics Committee of the Universidade Federal do Ceará (UFC), and the pregnant women provided their informed consent; the study was conducted according to the guidelines of the Helsinki Declaration regarding research involving human subjects.

An open clinical trial was conducted to evaluate maternal blood loss during childbirth by determining pre- and postpartum maternal hemoglobin levels in patients with misoprostol-induced labor compared with those in patients with non-induced labor. The study group included pregnant women admitted to the obstetric pathology service at the Maternidade Escola Assis Chateaubriand who were indicated for elective labor induction and were anticipating delivery. The control group included pregnant women with spontaneous labor that progressed to vaginal birth, and pregnant women who had an indication for elective cesarean without previous cesarean sections. The indications for elective cesarean were the following: fetal growth restriction, 
hypertensive disorders, breech position, and premature rupture of membranes with an unfavorable Bishop score.

The inclusion criteria were as follows: indication for elective labor induction (such as pre-eclampsia; HELLP syndrome (platelet level > 50,000/( $\mathrm{mm}^{3}$ ); chronic hypertension; prolonged pregnancy; pre-pregnancy diabetes mellitus; gestational diabetes; heart disease; and thyroid disease); gestation of a living fetus; vertex presentation; fetal weight estimated by ultrasound $>2,500 \mathrm{~g}$ and $<4,000 \mathrm{~g}$, according to the equation proposed by Hadlock et al; ${ }^{9}$ amniotic fluid index (AFI) $>5 \mathrm{~cm}$, except for cases of premature membrane rupture, in which AFI $<5 \mathrm{~cm}$ was allowed; normal prepartum basal cardiotocography; Bishop score $\leq 6$; and determination of pre- and postpartum hemoglobin levels. The exclusion criteria were as follows: one prior cesarean delivery; prior uterine scarring from myomectomy; anomalous presentation; evidence of altered fetal vitality (pre-partum cardiotocography, fetal biophysical profile, and/or Doppler of the umbilical artery); fetal growth restriction, with estimated fetal weight $<3$ percentile for the gestational age, according to the table proposed by Hadlock et al; ${ }^{10}$ multiple gestation; genital bleeding; and tumor structure, malformations, and/or ulcerations in the vulvoperineal region and birth canal. In all cases, the gestational age was determined by the date of the last menstrual period, and confirmed by an ultrasound performed in the first trimester.

Before induction, the pregnant women underwent basal cardiotocography, vaginal digital examination by an independent examiner to determine the Bishop score, obstetric transabdominal ultrasound to assess fetal position, estimation of fetal weight and AFI, and measurement of pre-partum hemoglobin levels. Postpartum hemoglobin was measured 24 hours after delivery. Further, each pregnant woman was administered a $25 \mu \mathrm{g}$ vaginal misoprostol tablet. Cardiotocography and vaginal examination were repeated to reassess the Bishop score every 6 hours, if the pregnant woman reported pain, or if fetal distress was suspected. A different obstetrician administered more tablets, up to a maximum dose of 6 tablets, during this period, until at least 2 uterine contractions lasting 30 seconds occurred within 10 minutes. Active labor was diagnosed when regular uterine activity was associated with a cervix dilated $>3 \mathrm{~cm}$ and completely effaced; at this time, the woman was transferred to the obstetric center, where she was monitored until delivery.

If the pregnant woman did not experience labor within 6 hours after administering the last tablet, and the Bishop score remained $\leq 6$, labor induction was considered a failure, and a cesarean delivery was conducted. In the presence of uterine tachysystole ( $\geq 5$ contractions in 10 minutes), the patient was instructed to rest in the left lateral decubitus position, and was rapidly hydrated with $1,000 \mathrm{~mL}$ of lactated Ringer's solution for 30 minutes. If the condition persisted, acute tocolysis was initiated with $20 \mathrm{mg}$ of oral nifedipine. When hyperstimulation syndrome (tachysystole associated with fetal heart rate changes) was diagnosed, the pregnancy was interrupted by cesarean section.

The sample size of each group was calculated based on the difference between pre- and postpartum hemoglobin levels in spontaneous vaginal births $(1.3 \pm 1.1 \mathrm{mg} / \mathrm{dL})$ and elective cesarean sections $(1.8 \pm 1.1 \mathrm{mg} / \mathrm{dL})$ obtained from a previous study conducted by Estafan et al. ${ }^{6}$ The result was a minimum of 28 cases in each group, with a significance level of $5 \%$ and a test power of $80 \%$, as proposed by Friendly ${ }^{11}$ for analysis of variance (ANOVA) for repeated measurements.

The data were entered into an Excel 2007 (Microsoft Corp., Redmond, WA, USA) spreadsheet, and analyzed using the SPSS (SPSS Inc., Chicago, IL, USA) software. The data were described using means, standard deviations (SDs), medians, minimums, maximums, absolute frequencies $(\mathrm{n})$, and relative frequencies (\%). Comparison of means (paired Student's $t$-test) and medians (Mann-Whitney, chi-square, or Fisher's exact test) and Spearman's rank correlation coefficient ( $r$ ) were used. Pre- and postpartum hemoglobin levels were evaluated using ANOVA for repeated measurements, in which the effects of time (the difference between pre- and postpartum hemoglobin levels, regardless of misoprostol use) and the effect of the group (the effect of misoprostol use on hemoglobin levels) were analyzed. A significance level $(p)$ of $<0.05$ was considered to be statistically significant.

\section{Results}

The studied group (misoprostol-induced labor) was constituted by 101 pregnant women: 53 vaginal deliveries, 46 cesarean sections, and 2 forceps deliveries. The control group included 60 pregnant women: 30 spontaneous vaginal deliveries and 30 elective cesareans.

The mean maternal age was $24.5 \pm 6.2$ years $(14-40$ years), and the mean number of pregnancies was $1.7 \pm 1.3$ (1-8). Sixty pregnant women (59.4\%) were nulliparous. The mean gestational age during induction was $39.5 \pm 1.8$ weeks (34.8-42.1). Of the induced deliveries, $42.5 \%$ resulted from prolonged pregnancies, and $24.7 \%$ from hypertensive disorders during pregnancy.

The Spearman's rank correlation coefficient between the number of misoprostol doses and the Bishop score at the beginning of the labor induction was significant ( $p=0.0059$ ) and negative ( $r=-0.27$ ), that is, a significant and inversely proportional but weak correlation was observed.

After misoprostol administration (misoprostol-induced labor group), 55 patients (54.4\%) progressed to vaginal delivery, 2 of which were resolved using forceps, whereas the other 46 patients (45.6\%) underwent cesarean section. The duration of labor progressing to vaginal delivery (55 cases) was up to 6 hours in 42 cases (76.4\%) and 6-12 hours in 13 cases (mean, $268 \pm 144.4$ minutes). Oxytocin was administered in $58.1 \%$ of the vaginal deliveries ( 32 cases), and the mean duration was $180.7 \pm 162.8$ minutes.

Cesarean section was indicated for the following motives: $59 \%$ ( 27 cases) for failed induction, $21.7 \%$ (10 cases) for acute fetal distress, $8.6 \%$ (4 cases) for functional dystocia, $8.6 \%$ ( 4 cases) for hypertensive disorders, and only $2.1 \%$ ( 1 case) for heavy vaginal bleeding.

Moreover, $27.7 \%$ of patients experienced nausea, $18.8 \%$ developed emesis, and $4.9 \%$ and $2.9 \%$ of the women reported hyperthermia and diarrhea respectively. There were no cases 
56 Can the Induction of Labor with Misoprostol Increase Maternal Blood Loss? Souza et al.

of uterine tachysystole or hyperstimulation syndrome. Of the 101 total cases, 10 (9.9\%) newborns were admitted to the neonatal intensive care unit (NICU), being 5 newborns delivered vaginally and 5 delivered by cesarean section, and no fetal or neonatal death was reported. - Table 1 presents the perinatal outcomes of the 101 cases that were evaluated.

When the variables were studied separately according to the type of delivery (vaginal or cesarean), no significant associations were found, except for the 1-minute Apgar score $<7$ (7.5\% versus $21.7 \%$ for vaginal and cesarean deliveries respectively, $p=0.0433$; - Table 2 ).

The mean pre- and postpartum hemoglobin levels in the group of mothers who delivered vaginally after induction were $12.0 \pm 1.2 \mathrm{mg} / \mathrm{dL}$ and $10.4 \pm 1.8 \mathrm{mg} / \mathrm{dL}$ respectively, with a postpartum decrease of $1.6 \pm 1.4 \mathrm{mg} / \mathrm{dL}$. The mean pre- and postpartum hemoglobin levels in the group of mothers who had spontaneous vaginal delivery were

Table 1 Perinatal outcomes of the 101 pregnant women (misoprostol-induced labor group) included in the study

\begin{tabular}{|c|c|c|}
\hline Perinatal outcome & $n$ & $\%$ \\
\hline \multicolumn{3}{|l|}{ Birth weight } \\
\hline $1,500-2,499 \mathrm{~g}$ & 4 & 4.0 \\
\hline $2,500-3,999 \mathrm{~g}$ & 90 & 89.1 \\
\hline$\geq 4,000 \mathrm{~g}$ & 7 & 6.9 \\
\hline \multicolumn{3}{|l|}{ Newborn weight } \\
\hline SGA & 1 & 1.0 \\
\hline AGA & 90 & 89.1 \\
\hline LGA & 10 & 9.9 \\
\hline \multicolumn{3}{|l|}{ 1-minute Apgar score } \\
\hline$<7$ & 15 & 14.9 \\
\hline$\geq 7$ & 86 & 85.2 \\
\hline \multicolumn{3}{|l|}{ 5-minute Apgar score } \\
\hline$<7$ & 1 & 1.0 \\
\hline$\geq 7$ & 100 & 99.0 \\
\hline \multicolumn{3}{|c|}{ Capurro method, in weeks } \\
\hline $0-37$ weeks & 9 & 8.9 \\
\hline $37.1-40$ weeks & 62 & 61.4 \\
\hline 40.1-41 weeks & 17 & 16.8 \\
\hline 41.1-42 weeks & 13 & 12.9 \\
\hline \multicolumn{3}{|c|}{ Classification according to maturity } \\
\hline Preterm birth & 6 & 5.9 \\
\hline Term & 93 & 92.1 \\
\hline Post-term birth & 2 & 2.0 \\
\hline \multicolumn{3}{|l|}{ Perinatal infection } \\
\hline Yes & 12 & 11.9 \\
\hline No & 89 & 88.1 \\
\hline
\end{tabular}

Abbreviations: AGA, appropriate for gestational age; LGA, large for gestational age; SGA, small for gestational age.
Table 2 Comparison of maternal and perinatal variables according to the type of delivery in the misoprostol-induced labor group

\begin{tabular}{|c|c|c|c|c|c|}
\hline & \multicolumn{4}{|c|}{ Type of delivery } & \multirow[t]{3}{*}{$p$} \\
\hline & \multicolumn{2}{|c|}{ Vaginal $^{\dagger}$} & \multicolumn{2}{|c|}{ Cesarean } & \\
\hline & $\mathrm{N}$ & $\%$ & $\mathrm{n}$ & $\%$ & \\
\hline \multicolumn{5}{|l|}{ Maternal age } & 1.0000 \\
\hline $0-18$ years & 10 & (18.9) & 8 & $(17.4)$ & \\
\hline $19-38$ years & 41 & $(77.4)$ & 37 & $(80.4)$ & \\
\hline$\geq 39$ years & 2 & $(3.8)$ & 1 & $(2.2)$ & \\
\hline \multicolumn{5}{|c|}{ Number of gestations } & 0.2781 \\
\hline 1 & 32 & $(60.4)$ & 27 & $(58.7)$ & \\
\hline 2 & 11 & $(20.8)$ & 14 & $(30.4)$ & \\
\hline 3 & 4 & $(7.5)$ & 4 & $(8.7)$ & \\
\hline$\geq 4$ & 6 & $(11.3)$ & 1 & $(2.2)$ & \\
\hline \multicolumn{5}{|l|}{ Parity } & 0.4219 \\
\hline 0 & 36 & $(67.9)$ & 35 & $(76.1)$ & \\
\hline 1 & 11 & $(20.8)$ & 8 & $(17.4)$ & \\
\hline 2 & 3 & $(5.7)$ & 2 & $(4.3)$ & \\
\hline 3 & 0 & $(0.0)$ & 1 & $(2.2)$ & \\
\hline$\geq 4$ & 3 & $(5.7)$ & 0 & $(0.0)$ & \\
\hline \multicolumn{5}{|l|}{ Bishop score } & 0.5009 \\
\hline 0 & 4 & $(7.5)$ & 4 & $(8.7)$ & \\
\hline 1 & 3 & $(5.7)$ & 7 & $(15.2)$ & \\
\hline 2 & 7 & $(13.2)$ & 7 & $(15.2)$ & \\
\hline 3 & 14 & $(26.4)$ & 13 & $(28.3)$ & \\
\hline 4 & 13 & $(24.5)$ & 11 & $(23.9)$ & \\
\hline 5 & 7 & $(13.2)$ & 3 & $(6.5)$ & \\
\hline 6 & 5 & $(9.4)$ & 1 & $(2.2)$ & \\
\hline \multicolumn{5}{|c|}{ 1-minute Apgar score } & $0.0433^{*}$ \\
\hline$<7$ & 4 & $(7.5)$ & 10 & $(21.7)$ & \\
\hline$\geq 7$ & 49 & $(92.5)$ & 36 & $(78.3)$ & \\
\hline \multicolumn{5}{|c|}{ 5-minute Apgar score } & 0.4646 \\
\hline$<7$ & 0 & $(0.0)$ & 1 & $(2.2)$ & \\
\hline$\geq 7$ & 53 & $(100.0)$ & 45 & $(97.8)$ & \\
\hline
\end{tabular}

Notes: *Chi-square test; ${ }^{\dagger}$ Two forceps deliveries were excluded.

$11.9 \pm 1.1 \mathrm{mg} / \mathrm{dL}$ and $10.5 \pm 1.4 \mathrm{mg} / \mathrm{dL}$ respectively, with a postpartum decrease of $1.4 \pm 1.0 \mathrm{mg} / \mathrm{dL}$ (- Fig. 1 ).

The mean pre- and postpartum hemoglobin levels in the group of mothers who had a cesarean section after attempted induction were $12.0 \pm 1.2 \mathrm{mg} / \mathrm{dL}$ and $10.6 \pm 1.3 \mathrm{mg} / \mathrm{dL}$ respectively, with a postpartum decrease of $1.5 \pm 1.0 \mathrm{mg} /$ $\mathrm{dL}$. Finally, the mean pre- and postpartum hemoglobin levels in the group of mothers who underwent elective cesarean section were $12.3 \pm 1.5 \mathrm{mg} / \mathrm{dL}$ and $10.6 \pm 1.5 \mathrm{mg} / \mathrm{dL}$ respectively, with a postpartum decrease of $1.8 \pm 1.1 \mathrm{mg} / \mathrm{dL}$ (-Fig. 2). 


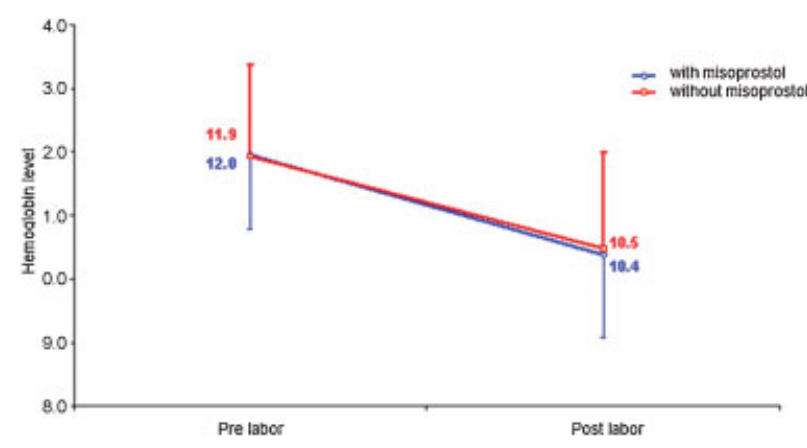

Fig. 1 Changes in hemoglobin levels during vaginal delivery.

We assessed the effect of time (the difference in hemoglobin levels during the pre- and post-partum periods, independently of misoprostol induction) and if misoprostol induction (groups with and without misoprostol induction) would change the hemoglobin level differently (group effect). We observed a significant difference regarding the effect of time in both types of delivery $(p<0.0001)$, but not between the groups $(\mathrm{p}>0.05)$. However, there were significant differences between the pre- and postpartum hemoglobin levels ( $p<0.0001$ ), but these differences were proportional between the groups with and without misoprostol administration, for both cesarean $(p=0.6845)$ and vaginal deliveries ( $p=0.2694 ;-$ Tables 3 and 4 ). For this analysis, the two cases of delivery with forceps were not

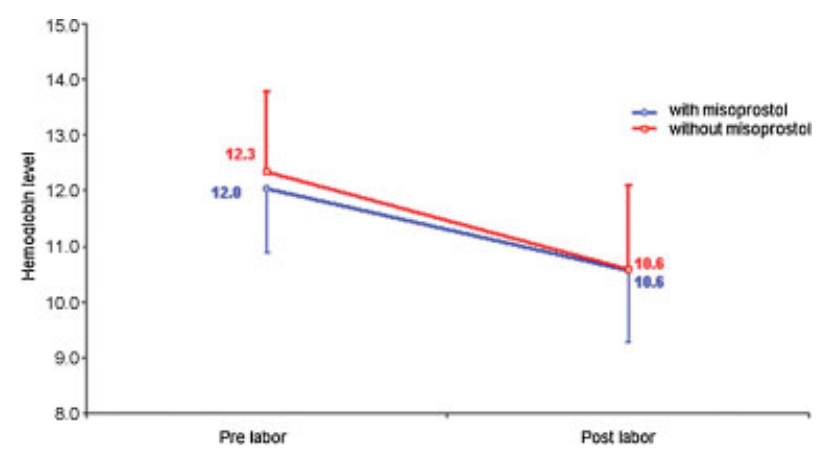

Fig. 2 Changes in hemoglobin levels during cesarean delivery.

considered, because this type of delivery is associated with greater blood loss.

\section{Discussion}

In this study, the patients were administered $25 \mu \mathrm{g}$ vaginal misoprostol every 6 hours. Zieman et al $^{12}$ performed the first pharmacokinetic study of misoprostol using the same route, and reported that the drug's plasma concentration gradually increased, reached the maximum level after 70-80 minutes, and gradually decreased; the drug could be detected 6 hours after administration. These authors observed that a $25 \mu \mathrm{g}$ dose was enough to trigger labor, but it did not increase the frequency of changes in uterine contractility.

Table 3 Hemoglobin levels during vaginal delivery

\begin{tabular}{|l|l|l|l|l|l|l|}
\hline & \multicolumn{2}{|l|}{$\begin{array}{l}\text { With } \\
\text { misoprostol } \\
(\boldsymbol{n}=53)^{\dagger}\end{array}$} & \multicolumn{2}{l|}{$\begin{array}{l}\text { Without } \\
\text { misoprostol } \\
(\boldsymbol{n}=30)^{\boldsymbol{f}}\end{array}$} & $\begin{array}{l}\text { Effect of the group } \\
\text { of Time }\end{array}$ \\
\hline Hemoglobin & Mean & SD & Mean & SD & \\
\hline Vaginal birth & 12.0 & 1.2 & 11.9 & 1.1 & & $p<0.0001^{*}$ \\
\hline Pre-partum & 10.4 & 1.8 & 10.5 & 1.4 & & \\
\hline Postpartum & 1.6 & 1.4 & 1.4 & 1.0 & & \\
\hline Pre-partum minus postpartum & & & & \\
\hline
\end{tabular}

Abbreviation: SD, standard deviation.

Notes: *Analysis of variance for repeated measurements; ${ }^{\dagger}$ Misoprostol-induced labor group; ${ }^{\int}$ control group.

Table 4 Hemoglobin levels during cesarean delivery

\begin{tabular}{|l|l|l|l|l|l|l|}
\hline & \multicolumn{2}{|l|}{$\begin{array}{l}\text { With misoprostol } \\
(\boldsymbol{n}=46)^{\dagger}\end{array}$} & \multicolumn{2}{l|}{$\begin{array}{l}\text { Without } \\
\text { misoprostol } \\
(\boldsymbol{n}=30)^{f}\end{array}$} & $\begin{array}{l}\text { Effect of } \\
\text { the group } \\
\text { time }\end{array}$ \\
\hline Hemoglobin & Mean & SD & Mean & SD & & \\
\hline Cesarean & 12.0 & 10.2 & 12.3 & 10.5 & & $p<0.0001^{*}$ \\
\hline Pre-partum & 10.6 & 10.3 & 10.6 & 10.5 & & \\
\hline Postpartum & 10.5 & 10.0 & 10.8 & 10.1 & & \\
\hline Pre-partum minus postpartum & & & \\
\hline
\end{tabular}

Abbreviation: SD, standard deviation.

Notes: *Analysis of variance for repeated measurements; ${ }^{\dagger}$ misoprostol-induced labor group; ${ }^{\int}$ control group. 
Labor was effectively induced in $73.2 \%$ of cases, and progressed to vaginal delivery in $54.4 \%$ of these cases. These results are in line with other studies documenting the effectiveness of misoprostol for inducing labor with a living fetus. The success rate of the misoprostol labor induction tends to be high compared with other methods of labor induction. $^{13,14}$

We observed a high rate of cesarean deliveries (45.5\%), which contradicts the majority of publications, in which the range is between $3.1 \%$ and $38.9 \% .{ }^{14-16}$ Sanchez-Ramos and Kaunitz $z^{15}$ published a meta-analysis of the effect of misoprostol on the rate of cesarean sections, with an analysis of data from 44 randomized clinical trials. They observed that the overall rate of cesarean sections and the rate of cesarean sections because of failed labor induction were significantly low in patients who received misoprostol. We observed a high rate of induction failure (59\%), which may be because of the low dose of misoprostol used, with a maximum of 6 tablets of $25-\mu \mathrm{g}$. In the study by Moraes Filho et al, ${ }^{17}$ the induction failure rate was lower, $\sim 7.5 \%$. However, they used more doses of misoprostol $(200 \mu \mathrm{g})$, whereas we used up to 6 tablets (150 $\mu \mathrm{g})$. Another risk factor for the high induction failure rate was the high proportion of nulliparous women in our sample (59.4\%), as previously mentioned. ${ }^{18}$

Of the 101 cases, only 10 newborns (9.9\%) required NICU admission. In a systematic review, Crane et $\mathrm{al}^{19}$ assessed the admission of newborns to the NICU in 9 studies involving a total of 801 pregnant women who underwent vaginal misoprostol-induced labor; these authors reported 53 hospitalizations (6.6\%), a number that was lower than the one found in our study.

Estafan et $\mathrm{al}^{6}$ evaluated blood loss using the postpartum hemoglobin decrease, and reported means of 1.3 and $1.8 \mathrm{mg} /$ $\mathrm{dL}$ for spontaneous vaginal delivery and elective cesarean section respectively. These values were similar to those obtained for the control group in our study for vaginal delivery and cesarean section without misoprostol ( 1.4 and $1.8 \mathrm{mg} / \mathrm{dL}$ respectively). ElSedeek et $\mathrm{al}^{8}$ evaluated blood loss during vaginal delivery in patients who were induced with $50 \mu \mathrm{g}$ of vaginal misoprostol and who were administered a second dose of $50 \mu \mathrm{g} 6$ hours after the first if there were no contractions. They observed that the mean blood loss measured using the postpartum hematocrit was of $6.90 \mathrm{mg} / \mathrm{dL}$; this value was higher than the one obtained in the present study, in which $25 \mu \mathrm{g}$ vaginal misoprostol was administered every 6 hours (with a maximum of 6 doses), inducing a mean postpartum hemoglobin decrease of $1.6 \mathrm{mg} / \mathrm{dL}$ after vaginal delivery. This lower postpartum hemoglobin decrease was probably associated with the lower dose of misoprostol used. There are no studies in the literature that report the impact of misoprostol induction on blood loss in patients who undergo cesarean delivery after attempted induction.

We observed significant differences in hemoglobin levels over time (pre- and postpartum) in both types of deliveries, but not between the groups (with and without misoprostol). However, the significant differences between the pre- and postpartum hemoglobin levels were proportional between the groups with and without misoprostol administration, for both cesarean and vaginal deliveries. It can be concluded that the postpartum hemoglobin decrease was statistically significant in all groups, that is, hemoglobin levels provide an effective estimation of blood loss during delivery. However, the results of the effect of misoprostol-induced labor on blood loss showed that misoprostol did not increase blood loss during induced vaginal delivery if compared with its effects during spontaneous vaginal delivery, and it did not increase blood loss during cesarean sections after attempted induction if compared with its effects during elective cesarean sections. These findings may be because of the $25 \mu \mathrm{g}$ misoprostol administration, which facilitates more gradual physiological changes in the cervix.

In conclusion, inducing labor with $25 \mu \mathrm{g}$ vaginal misoprostol every 6 hours, with a maximum of 6 doses, did not affect blood loss during the successfully induced vaginal deliveries or during cesarean sections after attempted induction.

\section{References}

1 Schoenhard G, Oppermann J, Kohn FE. Metabolism and pharmacokinetic studies of misoprostol. Dig Dis Sci 1985;30(11, Suppl) 126S-128S

2 Arias F. Pharmacology of oxytocin and prostaglandins. Clin Obstet Gynecol 2000;43(03):455-468

3 Sciscione AC, Nguyen L, Manley J, Pollock M, Maas B, Colmorgen G. A randomized comparison of transcervical Foley catheter to intravaginal misoprostol for preinduction cervical ripening. Obstet Gynecol 2001;97(04):603-607

4 Sarfati R, Maréchaud M, Magnin G. [Comparison of blood loss during cesarean section and during vaginal delivery with episiotomy]. J Gynecol Obstet Biol (Paris) 1999;28(01):48-54 French.

5 Larsson C, Saltvedt S, Wiklund I, Pahlen S, Andolf E. Estimation of blood loss after cesarean section and vaginal delivery has low validity with a tendency to exaggeration. Acta Obstet Gynecol Scand 2006;85(12):1448-1452

6 Estafan E, Spitzer A, Spitzer M, Sutija VG. The correlation of estimated blood loss with predelivery and postdelivery hemoglobin. Obstet Gynecol 2006;107(Suppl 4):30S

7 Jansen AJ, leNoble PJ, Steegers EA, van Rhenen DJ, Duvekot JJ. Relationship between haemoglobin change and estimated blood loss after delivery. BJOG 2007;114(05):657

8 ElSedeek MSh, Awad EE, ElSebaey SM. Evaluation of postpartum blood loss after misoprostol-induced labour. BJOG 2009;116(03): 431-435

9 Hadlock FP, Harrist RB, Carpenter RJ, Deter RL, Park SK. Sonographic estimation of fetal weight. The value of femur length in addition to head and abdomen measurements. Radiology 1984; 150(02):535-540

10 Hadlock FP, Harrist RB, Martinez-Poyer J. In utero analysis of fetal growth: a sonographic weight standard. Radiology 1991;181(01): 129-133

11 Friendly M. The SAS System for statistical graphics. Cary: SAS Institute; 1995

12 Zieman M, Fong SK, Benowitz NL, Banskter D, Darney PD. Absorption kinetics of misoprostol with oral or vaginal administration. Obstet Gynecol 1997;90(01):88-92

13 Hofmeyr GJ, Gülmezoglu AM. Vaginal misoprostol for cervical ripening and induction of labour. Cochrane Database Syst Rev 2003;(01):CD000941 
14 Alfirevic Z, Weeks A. Oral misoprostol for induction of labour. Cochrane Database Syst Rev 2006;(02):CD001338

15 Sanchez-Ramos L, Kaunitz AM. Misoprostol for cervical ripening and labor induction: a systematic review of the literature. Clin Obstet Gynecol 2000;43(03):475-488

16 How HY, Leaseburge L, Khoury JC, Siddiqi TA, Spinnato JA, Sibai BM. A comparison of various routes and dosages of misoprostol for cervical ripening and the induction of labor. Am J Obstet Gynecol 2001;185(04):911-915
17 Moraes Filho OB, Cecatti JG, Feitosa EF. [Methods for labor induction]. Rev Bras Ginecol Obstet 2005;27(08):493-500 Portuguese.

18 Seyb ST, Berka RJ, Socol ML, Dooley SL. Risk of cesarean delivery with elective induction of labor at term in nulliparous women. Obstet Gynecol 1999;94(04):600-607

19 Crane JM, Butler B, Young DC, Hannah ME. Misoprostol compared with prostaglandin E2 for labour induction in women at term with intact membranes and unfavourable cervix: a systematic review. BJOG 2006;113(12):1366-1376 